\title{
Is human immunodeficiency virus (HIV) a risk factor to development of dental caries and molar incisor hypomineralization (MIH) in children?
}

\author{
Arthur Musakulu Kemoli, Immaculate Opondo, Gladys Opinya
}

\begin{abstract}
Introduction: HIV-positive children are susceptible to various infections, and they are often placed on long-term medications to control and/or prevent these infections. It is possible that the ingestion of these medications by the children could resultin some form of dental conditions, like dental caries that possibly results from the intake of sugar-containing medications and poor oral hygiene, and or molar incisor hypomineralization (MIH) ensuing from the febrile conditions, ingestion of certain medications and/or other chemicals at the time the dentition is developing. Case Series: Two cases of HIV-positive children have been described in this paper, both of which suffered from severe dental caries and MIH. The treatment included extractions and extensive dental restorative procedures to improve their masticatory function and aesthetics. Conclusion: HIV-positive children may be at a greater risk of developing dental caries and MIH.
\end{abstract}

Keywords: Caries, Children, HIV-positive, Molar incisor hypomineralization (MIH)

Arthur Musakulu Kemoli ${ }^{1}$, Immaculate Opondo², Gladys Opinya $^{3}$

Affiliations: ${ }^{1} \mathrm{PhD}$, University of Nairobi, Associate Professor (Pediatric Dentistry), Department of Paediatric Dentistry \& Orthodontics Department, School of Dental Sciences, Nairobi, Kenya; ${ }^{2}$ MDS, Consultant Pediatric Dentist, Jaramogi Oginga Odinga Teaching and Referral Hospital, Kisumu, Kenya; ${ }^{3} \mathrm{PhD}$, Professor (Pediatric Dentistry), Department of Pediatric Dentistry \& Orthodontics Department, School of Dental Sciences, Nairobi, Kenya.

Corresponding Author: Arthur Musakulu Kemoli, P.O. Box 34848,00100 Nairobi, Kenya; Tel: +254 722436 481; Email: musakulu@gmail.com

Received: 09 February 2015

Accepted: 11 March 2015

Published: 08 April 2015

\section{How to cite this article}

Kemoli AM, Opondo I, Opinya G. Is human immunodeficiency virus (HIV) a risk factor to development of dental caries and molar incisor hypomineralization (MIH) in children? Edorium $J$ Dent 2015;2:15-20.

Article ID: 100005Do1AK2015

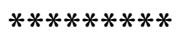

doi:10.5348/Do1-2015-5-CS-3

\section{INTRODUCTION}

Approximately, $30-40 \%$ and $15 \%$ of all cases of human immunodeficiency virus (HIV) in children from sub-Saharan countries and Europe respectively, contract the virus from their mothers during pregnancy, labor or breastfeeding $[1,2]$. These mothers will have contracted the virus, mainly, through blood transfusion, illicit drug use or sexual transmission. In spite of the high prevalence rate of HIV in the sub-Saharan population, antenatal HIV screening is still generally not compulsory in many of the countries [3]. Consequently, many women from the subSaharan region have their pregnancies progressing to full-term while unaware of their HIV status, the results of which are the continued increase in pediatric HIV/ AIDS cases in the region. Recent observations have demonstrated an increase in dental caries in HIV-positive child-population in both developed and less-developed nations, suggesting the possibility of a direct link of dental caries to immune-suppression [4]. Perhaps, confounding factors like poor oral hygiene, feeding practices, HIVrelated sicknesses and long-term use of medications [5], could be behind this trend. 
Dental caries basically results from the metabolic activities of Streptococci mutans, Lactobacilli within the dental plaque biofilm and a susceptible host, taking place over a period of time. The dental caries commences with a demineralization phase proceeding through a cavitation phase and ending up with in dental pulpal exposure phase [6]. The diagnosis of dental caries is mostly done through clinical and radiographic examinations. In its early stages of development, dental caries can be treated by the use of fluoride applications that aid in tooth remineralization. However, as the carious process continues unabated, then the treatment will change from the use of simple restorations of the cavitated lesions, to crowing of the affected teeth and worse still through endodontic treatment or as a last resort by extraction of the affected tooth $[7,8]$. The disease process may partly be compensated by good oral hygiene, fluoride exposure and non-cariogenic diet.

Another dental condition linked to certain systemic conditions and to the in-take of certain chemicals or medications, particularly in the early periods of dental development is molar incisor hypomineralization (MIH). The aetiology of MIH is non-specific, but the condition occurs during the transitional and maturation stages of amelogenesis. Though widely prevalent and less recognizable by many dental clinicians, MIH has commonly been associated with various prenatal, natal, postnatal sickness, disorders, toxins, medications, etc., occurring particularly during the period $\mathrm{o}-3$ years after birth [9]. MIH afflicts permanent first molars with or without involving the permanent incisors. Clinically, the affected teeth present with varied severity of MIH, and in its worst forms, it can result in premature loss of the affected tooth through either consistent tooth chipping or dental caries involvement [10].

The diagnosis of MIH is also clinical with the affected indexed teeth showing normal enamel thickness but demarcated opacities (altered enamel translucency) and distinct discoloration ranging from white-cream to yellow-brown. The teeth are often symptomatically sensitivity, difficult to anesthetize, susceptible to caries and commonly demonstrate repeated marginal breakdown of their characteristic atypical restorations. Radiographically, the teeth demonstrate reduced enamel density that closely matches that of the dentine [10].

In this paper, two HIV-positive children are described and an assessment made in regard to the integrity of their dentition, in relation to enamel developmental and the dental caries status of the dentition. A summary on the dental treatment provided to the patients has also been included.

\section{CASE SERIES}

Case 1: A 9-year-old HIV-positive boy accompanied by his widowed HIV-positive mother on antiretroviral (ARVs), reported to the out-patient department of a local clinic with a complaint of discolored teeth and pains from the lower posterior teeth provoked by chewing. Past medical history revealed that the boy had been born through a cesarean section with a weight of 2.8 kilograms at birth. After birth, he was not breast-fed, but, put through prevention of mother to child HIV transmission program. At the age of 6 years, he had uncomplicated dental extraction of one of his primary teeth. Enquiry on his dental habits revealed that the patient brushed his teeth twice a week, unassisted and unsupervised and he had a lip-sucking habit. At the time of consultation, the patient was in early mixed dentition with generalized extrinsic dental stains and multiple carious lesions. A five-day diet chart that had been requested earlier revealed evidence of a highly cariogenic diet for the patient. A review of the medication the patient was using showed that it contained a high amount of sucrose. All his permanent first molars had varying intensity of discoloration characteristic of MIH (Figure 1).

Panoramic or orthopantomogram (OPG) and bitewing radiographs (BW) taken of the patient showed the presence of permanent teeth in various stages of development and the primary teeth that were also in the oral cavity. The 46 and 36 had extensive carious lesions, but, less extensive carious lesions were seen on 55,65 , $75,85,16$ and 26 , with 16 and 26 also showing reduced enamel radio-density (Figure 1).

Based on the clinical and radiographic observations, a diagnosis of multiple carious teeth and MIH involving all the permanent first molars was arrived at. The patient was managed through improvement of the oral hygiene for the child and oral health literacy for the parent. A program of diet counseling was instituted and oral prophylaxis undertaken to remove the extrinsic stains. Restoration of the carious $36,46,75$ and 85 was initially done in glass ionomer, while 55, 65 were restored in compomer (Figure 2) and preventive resin restorations placed on 16 and 26. Stainless steel crown therapy was to be undertaken later for 46 and 36 , with definitive permanent crown therapy on the two teeth following after the age of 18 years. The patient was also put on a six-monthly fluoride varnish therapy programme in combination with the daily use of fluoridated toothpaste, and a three months recall. The initial psychological management therapy was used to help deter the lip sucking habit, which was to be monitored and if necessary further orthodontic intervention undertaken.

Case 2: A 7-year-old HIV-positive girl consulted a local university dental outpatient department complaining of decayed and broken teeth. Her past medical history revealed that she had been born normally with a weight of $3.2 \mathrm{~kg}$ and breastfed for a minimum of 6 months before being weaned off on other foods. Her HIV status had been established at the age of about 3 years and since then she had been placed on lamivudine, zidovudine and nevirapine as a single dose taken twice daily, besides the multivitamin syrup and cotrimoxazole tablets, which she also used. At the present consultation, the patient weighed $23 \mathrm{~kg}$ and was in very good general health. Her 
CD4 count was 1945 or $37.7 \%$ and the viral load was less than 40 ribonucleic acid copies per milliliter. The mother of the patient and the younger sibling had also been diagnosed as HIV-positive and were on ARVAs, while her older sibling was HIV-negative. The status of the father was unknown.

Extra-oral examination showed a young girl in fair general health, with symmetric facial features. Intra-oral examination revealed a patient in early mixed dentition, with erupting 36, 46, 41 and 31, a dental occlusion tending to Class III and a large anterior open bite, a result of a tongue thrusting habit. Her oral hygiene was very poor as nobody assisted or supervised her tooth brushing. Nearly all the teeth present in the oral cavity of the patient had caries (Figure $3(\mathrm{~A}-\mathrm{C})$. There were fluctuant swelling buccal to carious 64/65 and 54. The erupting lower permanent first molars had distinct discoloration.

Radiographic examination of her OPG and bite wing $\mathrm{X}$-rays, as shown in Figure $3 \mathrm{D}-\mathrm{F}$ ), revealed a developing dentition with multiple carious lesions involving nearly all the primary dentition. There was reduced radiodensity, almost matching closely with that of the dentine, of the enamel of all the permanent first molars. An analysis of the patient's lateral Cephalogram gave a Class III skeletal pattern with an anterior open bite. One-week diet intake that had been sought showed the child to be on a high carcinogenic diet.

On the basis of the clinical and radiographic findings for this case, a diagnosis of rampant caries and MIH was arrived at. The global management of the case included oral hygiene education, oral prophylaxis, fluoride therapy, extractions of the extensively carious teeth, restorations of the restorable carious teeth in compomer and composite. An appropriate prosthesis was to be fabricated to initially enhance masticatory function, aesthetics and incorporating a habit breaker for the tongue thrust (Figure 4). Thereafter the patient was to be followed so that a definitive orthodontic treatment could follow at a later stage.

\section{DISCUSSION}

Parents or guardians of children with HIV find themselves overburdened by the medical, physical, psychological and emotional needs of their children, and dental issues will not usually appear high up on their priority list, until problems arise. Due to progressive decrease in the number of $\mathrm{CD} 4$ cells in these patients, that render themseverely immune-suppressed host, susceptible to secondary infections, that could include oral infections [11]. These patients are, therefore, often placed on some form of oral medication over long periods of time as exemplified in the two cases described in this paper. Long-term prophylactic medication, with the possibility of some of the medications containing sucrose [12] and even other substances, could result in some form of dental disease or disorder. To improve the mortality
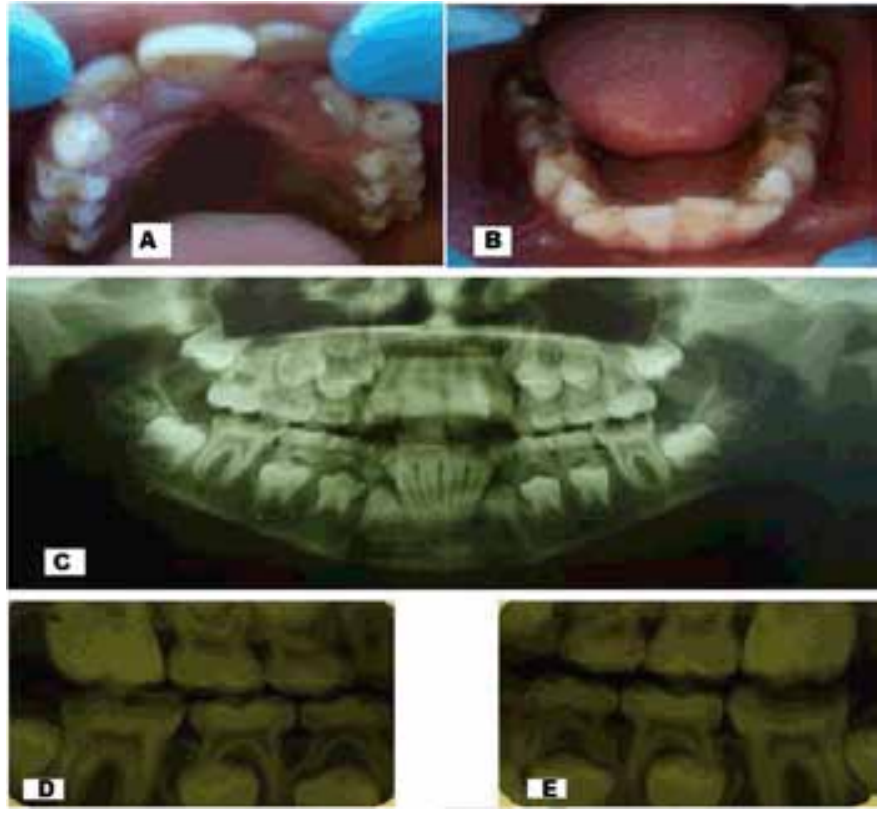

Figure 1: Intraoral photographs (A, B) and radiographs OPG (C) and (D, E) BW showing generalized extrinsic stains, discolored permanent first molars, and multiple carious teeth involving primary dentition and the permanent first molars with reduced enamel radio-density.
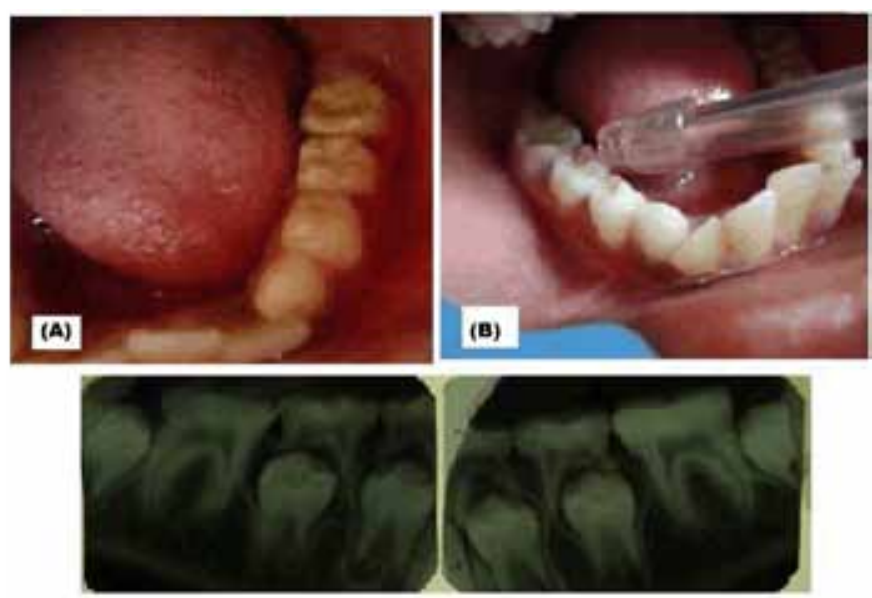

(c)

Figure 2: (A) Intraoral photographs, and (B) Radiographs (BW) showing the dentition after treatment of extrinsic stains, and (C) The restoration of the carious teeth but prior to stainless steel therapy for the 36 and 46 .

and morbidity of the affected teeth, early consultation with the dentist could provide an opportunity for early prevention, diagnosis of dental caries and MIH that could result from the effects of these medications.

The possibility of a large number of young children, particularly from low socioeconomic background, is suffering from medical conditions like HIV is real. These children could be at a higher risk of developing dental caries [13] and or MIH as a result of the environmental conditions in which they live and the effects of the medicines and foods provided to them. The high caries 

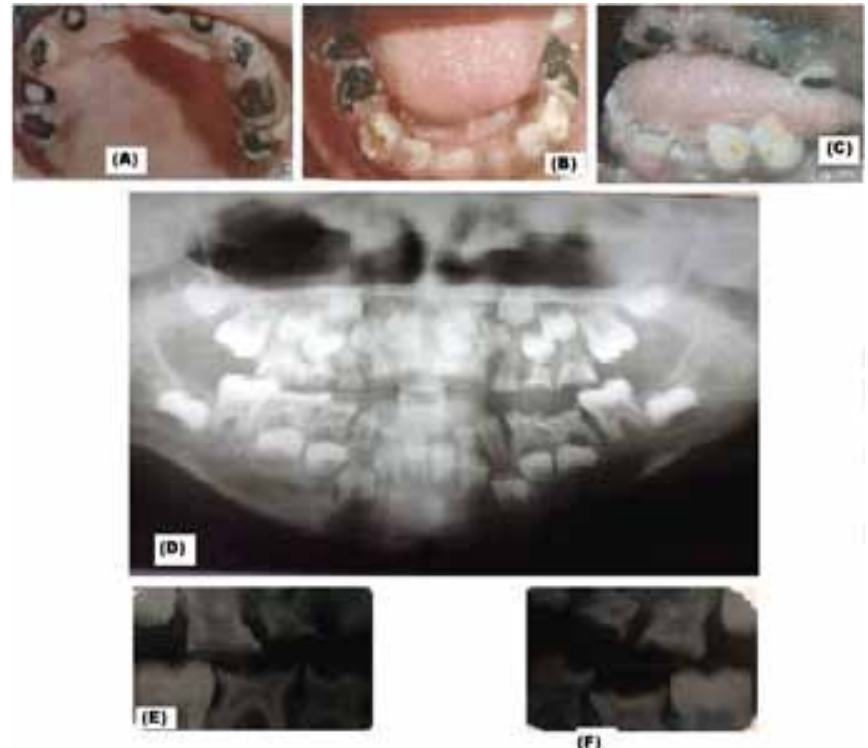

Figure 3: (A-C) Intraoral photographs and (D) Radiographs OPG and (E, F) BW of the girl showing rampant caries, anterior open bite.
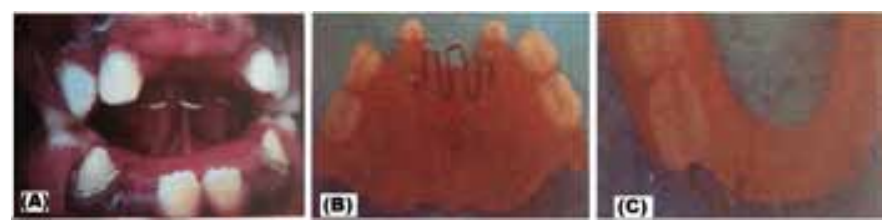

Figure 4: Intraoral photographs of the girl showing (A) Upper and lower acrylic dentures/habit breaker inserted in the mouth, and $(\mathrm{B}, \mathrm{C})$ The photographs of the two appliances when outside the mouth.

experience in these patients, could be attributed to the poor oral hygiene observed, the high intake of sugary medication and probably some salivary gland dysfunction (like Xerostomia) that is often associated with antiretroviral drugs [14-16]. On the contrary, other researchers have reported lower prevalence of caries in children with perinatal HIV infections [17]. A number of ARV medications are now also available as sugar-free preparations, but the sugar-containing preparations could probably be more readily available and preferred by the patient's guardian because of their low-cost, higher compliance by child or as the only ones available at the time of dispensing. Nonetheless, higher caries incidences in these children can only mean higher numbers of extractions, restorations and prostheses, leading to higher expenses to the parent/guardian and hence a bigger burden [18].

The global prevalence of MIH has been reported to be as low as $2.8 \%$ and as high as $40.2 \%$ [19]. This condition has been associated with specific genes, and a variety of environmental factors, such as toxins, medications, preand post-natal illness, low birth weight, malnutrition during the first three years of life [20]. For the two cases described in this paper, the children had been put on ARVs at different stages of their early lives, and in one case the child was also using multivitamins and antibiotics. It is possible in both cases that the ARV medication they were taking could have contributed to the poor condition of their dentition [20, 21]. Further, HIV usually predisposes the child-patient to frequent infections and fevers. It is possible that the two cases described could have suffered from some form of febrile infections that could have affected the dental calcification process at the time when the permanent first molars and the incisors were undergoing mineralization.

The effects to the child of the two dental conditions described in this paper would be in relation to their dental aesthetics, dental hypersensitivity, rapid tooth-wear and susceptibility to dental caries, which in turn would result in extensive treatment needs and dental anxiety [9]. The possible management of the conditions would include fluoride, micro-abrasion, bleaching, composite/ porcelain, veneers, sealants, preventive resin restoration, crowning (stainless steel crowns or porcelain), extractions and dental prosthesis. In certain instances the option of extraction of the permanent first molars with/without orthodontic repositioning of second molars can be considered [22]. In the case of the two patients described in this paper, these options were carefully considered, including the financial implication to the caregiver so as to arrive at the definitive treatment that was provided. Primarily, improvement of their oral hygiene, function and aesthetics were the major concerns for the two cases described, so as to initially help enhance the oral healthrelated quality-of- life of the two children [23].

\section{CONCLUSION}

An HIV-positive child on ARVs/other medications could be at risk for dental caries and Molar incisor hypomineralization (MIH), and early intervention should be considered as a model of reducing the risk to dental caries and MIH the two dental conditions and also enhancing the oral health-related quality-of-life of the child. Consideration should be given to the caregivers in terms of provision of information on the dental prognosis of such children, and the requisite motivation provided to improve the oral hygiene of the child and the access to available oral health facilities as a means of reducing the risk of the child developing the two conditions.

$* * * * * * * * *$

\section{Acknowledgements}

The authors acknowledge the parents and the children who consented to the use of this data contained in this manuscript.

\section{Author Contributions}

Arthur M. Kemoli - Conception and design, Acquisition of data, Analysis and interpretation of data, Drafting the 
article, Critical revision of the article, Final approval of the version to be published

Immaculate Opondo - Acquisition of data, Critical revision of the article, Final approval of the version to be published

Gladys Opinya - Acquisition of data, Drafting the article, Final approval of the version to be published

\section{Guarantor}

The corresponding author is the guarantor of submission.

\section{Conflict of Interest}

Authors declare no conflict of interest.

\section{Copyright}

(C) 2015 Arthur M. Kemoli et al. This article is distributed under the terms of Creative Commons Attribution License which permits unrestricted use, distribution and reproduction in any medium provided the original author(s) and original publisher are properly credited. Please see the copyright policy on the journal website for more information.

\section{REFERENCES}

1. The Working Group on Mother-to-child Transmission of HIV (1995) Rates of mother-to-child transmission of HIV-1 in Africa, America, and Europe: Results from 13 perinatal studies. J Acquir Immune DeficSyndr Hum Retrovirol 8:506-10.

2. Lewis AD. HIV Sexually transmitted infections epidemiology, management and control in the IUSTI Africa region: Focus on Su-Saharan Africa. Sex Transm Infect, 2011; 87(2): 10-13.

3. UNAIDS, Regional fact sheet 2012.

4. Valdez IH, Pizzo PA, Atkinson JC (1994) Oral health of pediatric AIDS patients: A hospital-based study. ASDC J Dent Child 61:114-8.

5. Gehrke FS, Johnsen DS (1991) Bottle caries associated with anti-HIV therapy. Pediatr Dent 13:73.

6. Harris R, Nicoll AD, Adair PM, Pine CM (200\$) Risk factors for dental caries in young children: A systematic review of the literature. Community Dent Health 21:71-85.

7. Fejerskov O, Thylstrup A. Different concepts of dental caries and their implications. Textbook of Clinical Cariology, 2nd Ed. Munksgaard, Copenhagen, 1994.,Chapt 9.

8. Featherstone JD. Dental caries: a dynamic disease process. Aust Dent J, 2008; 53(3): 286-91.

9. JälevikB,NorénJG(2000)Enamelhypomineralization of permanent first molars: A morphological study and survey of possible aetiological factors. Int J Paediatr Dent 10:278-89.

10. Weerheijm KL, Jälevik B, Alaluusua S. Molar Incisor Hypomineralisation. Caries Res, 2001; 35(5): 390391.

11. Chigurupati R, Raghavan SS, Studen-Pavlovich DA (1996) Paediatric HIV infection and its oral manifestations: a review. Paediatr Dent 18:106-113.
12. Maguire A, Rugg-Gunn AJ (1994) Prevalence of longterm use of liquid oral medicines by children in the northern region, England. Community Dent Health 11:91-6.

13. Nunn JH (1990) Handicap in perspective. In: Murray JJ, editor. The Prevention of Dental Disease. 2nded. New York: Oxford University Press; , p. 13.

14. Madigan A, Murray PA (1996) Houpt M, Catalanotto F, Feuerman M. Caries experience and cariogenic markers in HIV-positive children and their siblings. Pediatr Dent 18:129-36.

15. Ribeiro AA, Portela MB, de Souza IPR (2013) The oral health of HIV-infected Brazilian children. Int J Paediatr Dent 23(5): 359-365.

16. Subramaniam P, Kumar K. Cariogenic potential of medications used in treatment of children with HIV infection. Spec Care Dentist. 2014; 34(3):127-30.

17. Sahana S, Krishnappa SS, Krishnappa VS. Low prevalence of dental caries in children with perinatal HIV infection. J Oral Maxillo-facPathol, 2013; 17(2): 212-6.

18. Selwitz RH, Ismail AI, Pitts NB. Dental caries. The Lancet, 2007; 369: 51-59.

19. Soviero V, Haubek D, Trindade C, Da Matta T, Poulsen $S$ (2009) Prevalence and distribution of demarcated opacities and their sequelae in permanent 1st molars and incisors in 7 to 13 -year-old Brazilian children. ActaOdontolScand 67:170-5.

20. Jälevik B, Norén JG, Klingberg G, Barregård L (2001) Etiologic factors influencing the prevalence of demarcated opacities in permanent first molars in a group of Swedish children. Eur J Oral Sci 109:230-4.

21. Trigueiro M, Tedeschi-Oliveira SV, Melani RF, Ortega KL (2010) An assessment of adverse effects of antiretroviral therapy on the development of HIV positive children by observation of dental mineralization chronology. J Oral Pathol Med 39:3540.

22. Leppaniemi, A., Lukinmaa, P.L. and Alaluusua, S. 2001. Non-fluoridehypomineralizations in the permanent first molars and their impact on the treatment need. Caries Res 35:36-40.

23. Rovaris NS, Galato D, Schuelter-Trevisol F, da Silva J, LinharLda S, Nickel DA, Traebert J. Oral health status and its impact on the quality of life of children and adolescents living with HIV-1. BMC Res Notes. 2014 Jul 28;7:478. 


\section{ABOUT THE AUTHORS}

Article citation: Kemoli AM, Opondo I, Opinya G. Is human immunodeficiency virus (HIV) a risk factor to development of dental caries and molar incisor hypomineralization (MIH) in children? Edorium J Dent 2015;2:1520.

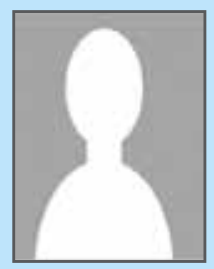

Arthur M. Kemoli is the Chairman at the Department of Paediatric Dentistry and Orthodontics, School of Dental Sciences, University of Nairobi, Nairobi, Kenya. He earned the undergraduate degree BDS from School Of Dental Sciences, University of Nairobi, Nairobi, Kenya and postgraduate degree MSC (Paediatric Dentistry) from Department of Cariology, Endodontology and Paedodontology, ACTA, University of Amsterdam, Amsterdam, The Netherlands. He holds a PhD Degree in Paedodontology from the University of Amsterdam, Amsterdam, The Netherlands. He has published 23 research papers in national and international academic journals, contributed chapters to two books and authored two books. His research interests include new approaches to the management of dental caries and dental developmental issues. He intends to pursue research in the two areas with a possibility of a Postdoc) in future.

E-mail:musakulu@gmail.com

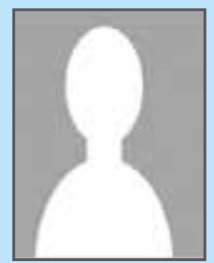

Immaculate Opondo is a Paedodontist at Jaramogi Oginga Odinga Teaching and Referal Hospital, Kisumu City, Kenya. She earned the undergraduate degree BDS from University of Nairobi, Kenya and postgraduate degree MDS-Paediatric Denstistry from University of Nairobi, Kenya. She has published no research papers in national and international academic journals and authored no books. Her research interests include, Oral Health Related Quality of life, Dental caries and issues affecting the Special child. She intends to pursue $\mathrm{PhD}$ in future.

E-mail: immachamasa@yahoo.com

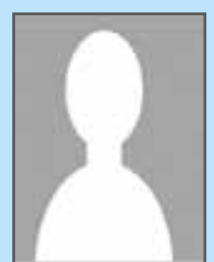

Gladys Opinya, Professor of Paediatric Dentistry, Department of Paediatric Dentistry, School of Dental Sciences. College of Health Sciences . University of Nairobi, Kenya. She earned the Bachelor of Dental Surgery degree at the University of Nairobi Kenya, and postgraduate diploma and degree form CAGS and an MSc Pedontontics Department of Paediatric Dentistry at the Henry Goldman School of Graduate Dentistry, Boston University, United States America University. She is a holder of a PhD in Dental Surgery of the University of Nairobi. She has published over twenty research papers in national and international academic journals. Her research interests include fluoride, nutrition in children and infants, early chihood caries. She intends to pursue resease on fluoride, nutrion and early childhood caries in future for academic interest and to influence local national policy.

E-mail: gladys.opinya@uonbi.co.ke

Access full text article on other devices

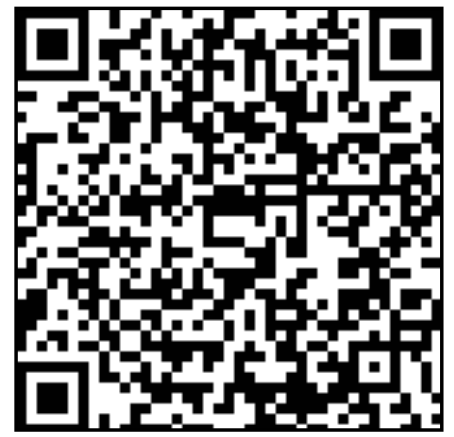

Access PDF of article on other devices

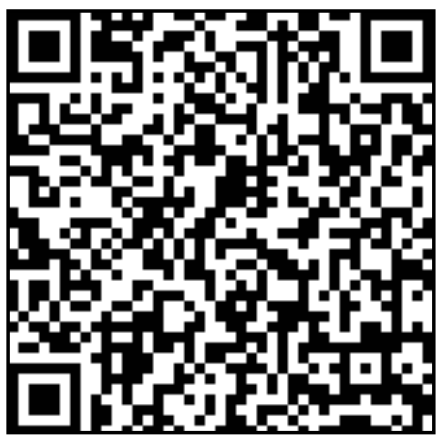

